\title{
Improving the influenza vaccination rate in patients visiting pediatric rheumatology clinics using automatic best practice alert in electronic patient records
}

Anjali Patwardhan*, Kelly Kelleher, Dennis Cunningham, Charles Spencer

From 2011 Pediatric Rheumatology Symposium sponsored by the American College of Rheumatology Miami, FL, USA. 2-5 June 2011

\section{Purpose}

Children with rheumatic disease who are infected with influenza have increased rates of complications. Influenza-related morbidity and mortality can be reduced by improving the flu vaccination rate. The purpose of the study is to look at the effectiveness of single information technology intervention in improving flu vaccination rate in children with rheumatic diseases.

\section{Methods}

We examined three yearly cohorts $(2007,2008$, and 2009) of rheumatology clinic patients from a large pediatric

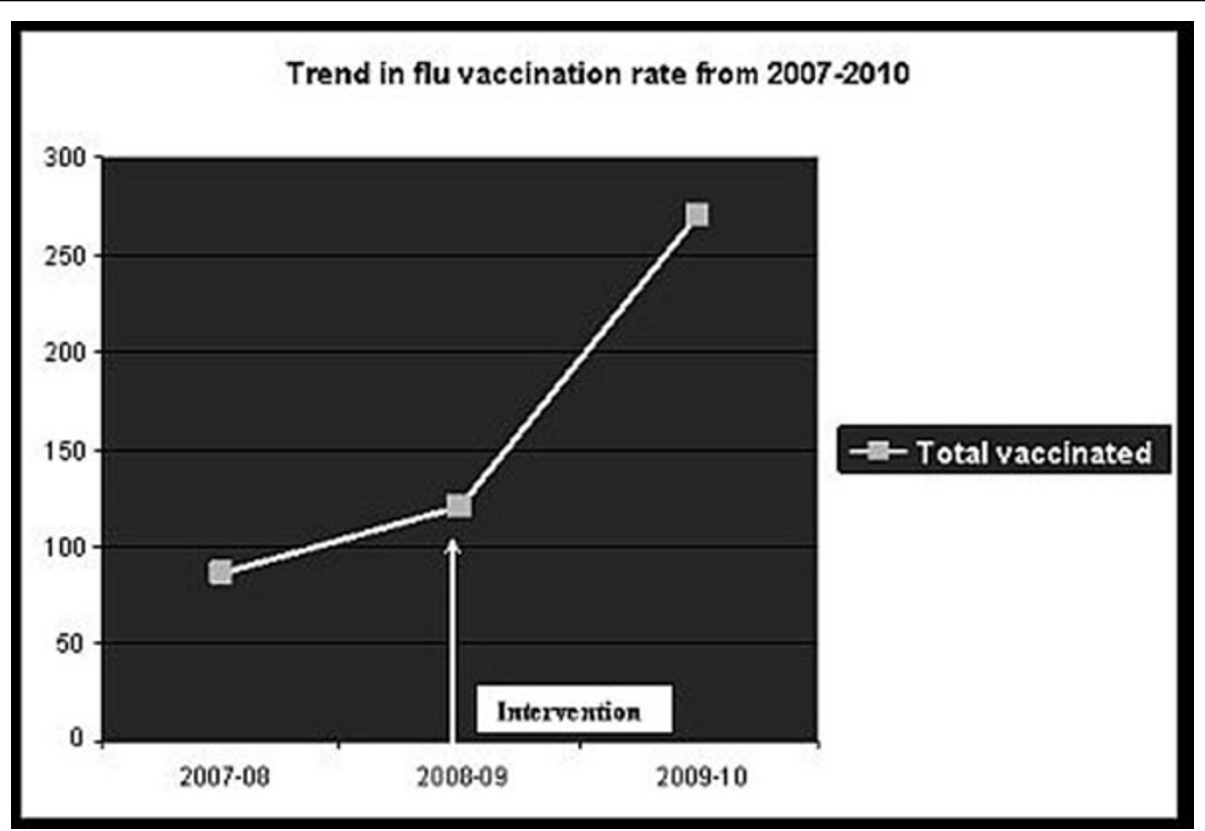

Figure 1

The Ohio State University and Nationwide Childrens Hospital, Columbus, $\mathrm{OH}$, USA

(c) 2012 Patwardhan et al; licensee BioMed Central Ltd. This is an Open Access article distributed under the terms of the Creative 
hospital for evidence of influenza vaccination in the electronic health record. We introduced an electronic health record (EHR) intervention automatic best practice alert reminder in our patients' records from September 2009 until the end of the influenza season. We compared claims-based records of receipt over 3 years and conducted a Delphi survey of stakeholders after the flu season. In 2009, an EHR automatic best practice alert reminder to vaccinate patients was introduced. Using Clarity Report Write for EPIC, each chart was examined for evidence of influenza vaccination in order to test for vaccination rate difference amongst the cohorts. We employed logistic regression equations to control for possible confounders (age, sex, ethnicity, insurance status, distance from clinic and attending physician) using SAS 9.1.3. We conducted qualitative interviews with participating clinicians to assess their perspectives on the addition of the reminder.

\section{Results}

There was a significant difference in the probability of being vaccinated before and after intervention ( $p$ value $<0.0001$ ). With the rate increased from $5.9 \%$ in 2007 and $7.8 \%$ in 2008 to $25.5 \%$ in 2009 . All three years, individual attending's contribution and ethnicity of patients had significant effects on vaccination rate. Confounders such as age, sex, insurance status and distance from clinic had no effect on the vaccination rate.

\section{Conclusion}

EHR-embedded information in past studies has been only modestly effective in improving care for many chronic conditions. Our automatic best practice alert reminder for flu-vaccine appears to be effective for changing behaviors and improving the vaccination rate in rheumatology clinics.

\section{Disclosure}

Anjali Patwardhan: None; Kelly Kelleher: None; Dennis Cunningham: None; Charles Spencer: None.

Published: 13 July 2012

doi:10.1186/1546-0096-10-S1-A106

Cite this article as: Patwardhan et al:: Improving the influenza vaccination rate in patients visiting pediatric rheumatology clinics using automatic best practice alert in electronic patient records. Pediatric

Rheumatology 2012 10(Suppl 1):A106.
Submit your next manuscript to BioMed Central and take full advantage of:

- Convenient online submission

- Thorough peer review

- No space constraints or color figure charges

- Immediate publication on acceptance

- Inclusion in PubMed, CAS, Scopus and Google Scholar

- Research which is freely available for redistribution

Submit your manuscript at www.biomedcentral.com/submit 